3-14-2017

\title{
Low cost quality initiatives for management of neurosurgical patients in developing nations: Perspective from a tertiary care centre in Pakistan
}

Hamid Hussain Rai

Muhammad Waqas

Muhammad Shahzad Shamim

Follow this and additional works at: https://ecommons.aku.edu/pakistan_fhs_mc_surg_neurosurg

Part of the Neurology Commons, Neurosurgery Commons, and the Surgery Commons 


\title{
Low cost quality initiatives for management of neurosurgical patients in developing nations: Perspective from a tertiary care centre in Pakistan
}

\author{
Hamid H. Rai, Muhammad Waqas, Muhammad S. Shamim \\ Department of Surgery, Section of Neurosurgery, Aga Khan University Hospital, Karachi, Pakistan \\ E-mail: Hamid H. Rai - hamidhussainrai@hotmail.com; MuhammadWaqas - waqas.muhammad@aku.edu; \\ *Muhammad S. Shamim - shahzad.shamim@aku.edu \\ *Corresponding author
}

Received: 24 August $16 \quad$ Accepted: 12 January $17 \quad$ Published: 14 March 17

\begin{tabular}{|c|c|}
\hline bstract & \\
\hline $\begin{array}{l}\text { Background: Targeting resources on cost-effective care strategies is pertinent } \\
\text { for developing nations, specifically for already burdened specialties such as } \\
\text { neurosurgery, where without state support and insurance companies, expenses } \\
\text { are borne by the patient themselves. }\end{array}$ & \\
\hline $\begin{array}{l}\text { Methods: This was a descriptive review of literary work published by the section } \\
\text { of neurosurgery at Aga Khan University Hospital, Pakistan. We searched PubMed } \\
\text { and CiNAHL databases to identify articles, which were then critically analyzed and } \\
\text { discussed from a perspective of low-cost quality care. }\end{array}$ & \\
\hline Results: We demonstrate the cost effectiveness of three initiatives, namely, blood & Access this article online \\
\hline $\begin{array}{l}\text { ordering protocol for elective spine arthrodesis, nonoperative management being } \\
\text { superior to surgical stabilization in spine injury patients with complete neurological }\end{array}$ & $\begin{array}{l}\text { Website: } \\
\text { www.surgicalneurologyint.com }\end{array}$ \\
\hline $\begin{array}{l}\text { deficits, and early tracheostomy in patients with isolated severe traumatic brain } \\
\text { injury. }\end{array}$ & $\begin{array}{l}\text { DOI: } \\
\text { 10.4103/sni.sni_352_16 } \\
\end{array}$ \\
\hline $\begin{array}{l}\text { Conclusion: Initiation and implementation of such cost-effective strategies without } \\
\text { compromising quality health standards must be emphasized by neurosurgical } \\
\text { centers throughout the developing world for smart allocation and utilization of funds. }\end{array}$ & Quick Response Code: \\
\hline $\begin{array}{l}\text { Key Words: Blood transfusion protocol, cost effectiveness, early tracheostomy, } \\
\text { pinal cord injury }\end{array}$ & 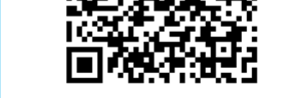 \\
\hline
\end{tabular}

\section{INTRODUCTION}

With a per capita income of PKR 153,060 (2015), Pakistan is classified by the World Health Organization as a low middle-income country. Cost is a serious consideration for our patients, especially in the private health sector, where without state support and insurance companies, expenses are borne by the patients themselves. ${ }^{[11]}$ Health care concerns focus on the concept of value, defined as a composite of cost, quality, and access. This emphasis on value is undermined by
This is an open access article distributed under the terms of the Creative Commons Attribution-NonCommercial-ShareAlike 3.0 License, which allows others to remix tweak, and build upon the work non-commercially, as long as the author is credited and the new creations are licensed under the identical terms.

For reprints contact: reprints@medknow.com

How to cite this article: Rai HH,Waqas M, Shamim MS. Low cost quality initiatives for management of neurosurgical patients in developing nations: Perspective from a tertiary care centre in Pakistan. Surg Neurol Int 2017;8:35.

http://surgicalneurologyint.com/Low-cost-quality-initiatives-for-management-ofneurosurgical-patients-in-developing-nations:-Perspective-from-a-tertiary-carecentre-in-Pakistan/ 
a lack of correlation between the increase in health care spending in recent years and health outcomes, which is often contributed by a lack of information and tracking outcomes to determine the value of different treatments. ${ }^{[6]}$ This increase in health care cost without direct improvements in health outcomes coupled with a desire to expand access to the large uninsured population has underscored the importance of quality initiatives that provide more affordable health care by maximizing value. Therefore, we must identify areas where costs could be significantly cut without impacting the quality of care.

\section{MATERIALS AND METHODS}

We searched PubMed and CiNAHL databases for articles published by the department of neurosurgery at Aga Khan University Hospital, Pakistan. The terms "Aga Khan University Hospital," "Neurosurgery," or "Research" were used to run search on two separate occasions, i.e., 8 May and 20 May 2016. We selected all the articles in which the studies were carried out at the Aga Khan University Hospital, irrespective of date of publication. The articles were then critically analyzed and discussed from a perspective of low cost quality care, with reference to the available international literature.

The prospective validation of blood ordering protocol was a cross-sectional study conducted during the year 2012. All adult patients who underwent elective spinal arthrodesis were included and prospectively observed. The actual transfusion index was calculated for individual patients with the formula $\mathrm{Cl} / \mathrm{T}$, where $\mathrm{Cl}$ is the number of units of packed red blood cells (RBCs) cross matched and $\mathrm{T}$ is the number of actual transfusions. $\mathrm{Cl} / \mathrm{T}$ was then compared with a theoretical transfusion index $\mathrm{C} 2 / \mathrm{T}$ for the same group of patients; $\mathrm{C} 2$ being the number derived from calculating the number of units of packed RBCs that would have been ordered for individual patient according to the protocol. The cost difference between $\mathrm{Cl} / \mathrm{T}$ and $\mathrm{C} 2 / \mathrm{T}$ was analyzed.

A detailed retrospective analysis of all patients admitted from 2004 to 2010 with "complete injury," i.e., patients with either complete spinal cord injury (SCI) or complete deficits following traumatic spine injury presenting within 14 days of injury were included. Complete SCI was defined as patients having no motor or sensory function below the neurological level, no preserved function in sacral segments S4-S5, and confirmed on the basis of MRI of affected region showing complete disruption of the spinal canal. Included patients were divided into two groups, those who underwent stabilization procedures and those who were managed nonoperatively. Both groups were compared with the outcome parameters being time to rehabilitation, length of hospital stay, 30-day morbidity/ mortality, cost of treatment, and status at follow-up. Rehabilitation was defined as mobilization from bed up to the chair or wheelchair, and status at follow-up was measured in terms of axial pain or mobilization at follow-up.

Patients with isolated severe traumatic brain injury (TBI), defined as a Glasgow Coma Scale (GCS) score $<8$, requiring airway control and ventilation were included in a 7-year review. Early tracheostomy (ET) was defined as tracheostomy within 7 days of TBI, and prolonged endotracheal intubation (EI) as EI exceeding 7 days of TBI. All patients were comparable in terms of age and initial GCS, and both groups were evaluated regarding clinical outcome in terms of ventilator-associated pneumonia (VAP), intensive care unit (ICU) stay, and Glasgow Outcome Scale (GOS).

\section{RESULTS}

A total of 125 patients were included for the blood ordering protocol and a total of 435 units of packed RBCs were ordered $(\mathrm{Cl})$, out of which only 108 units were transfused $(\mathrm{T})$, yielding a $\mathrm{Cl} / \mathrm{T}$ of 4.02 . The $\mathrm{C} 2$ for the same group of patients was 188 units of packed $\mathrm{RBCs}$, and the $\mathrm{C} 2 / \mathrm{T}$ was thus calculated to be 1.74 . Implementation of the protocol would reduce per patient cost from Pakistani Rupees (PKR) $6676.8 \pm 4125.8$ to $4700.8 \pm 1712.86(P<0.001)$, with an overall cost reduction of $30 \%$.

Fifty-four patients fulfilled the inclusion criteria for complete SCI, and half of these patients were operated. On comparing endpoints, patients in the operative group took longer time to rehabilitation $(P=0.002)$; had longer hospital stay $(P=0.006)$, which included longer length of stay in special care unit $(P=0.002)$ as well as intensive care unit $(P=0.004)$; and were associated with more complications, especially those related to infections $(P=0.0027)$. The mean cost of treatment was also significantly higher in the operative group, being USD 6500 compared to that of the nonoperative group of USD $1490(P<0.001)$.

Of the 100 patients with severe TBI, 49 underwent ET and 51 remained on prolonged EI for ventilation. Evaluation of both the groups regarding clinical outcome in terms of VAP showed higher frequency in the EI group relative to the ET group (63\% vs. $45 \%$; $P=0.09)$. ET group showed significantly less ventilator days (10 days vs. 13 days; $P=0.031$ ), ICU stay ( 11 days vs. 13 days; $P=0.030)$, complication rate $(14 \%$ vs. $18 \%)$, and mortality $(8.2 \%$ vs. $17.6 \%)$. Clinical outcome assessed on the basis of GOS was also better in the ET group, and most importantly, total inpatient cost of USD 8027 in the ET group was considerably less compared with USD 9961 of the EI group. 


\section{DISCUSSION}

With innovations regarding the safety and efficacy of spinal arthrodesis, the number of complex reconstructive fusion procedures is increasing. ${ }^{[4]}$ Although historically such procedures were associated with major blood loss, recent advances in surgical techniques, methods of hemostasis, and improved anesthetic and perioperative management strategies have significantly reduced operative blood loss but have not eliminated operative transfusion requirements. ${ }^{[10]}$ With no specific evidence-based guidelines regarding the appropriate amount of blood products to be ordered prior to specific spinal procedures - the respective blood loss and transfusion requirements are being overestimated. ${ }^{[9]}$ It has been repeatedly stressed that patients undergoing elective spine arthrodesis tend to have more blood products arranged than what would be eventually required, therefore, generally yielding a high transfusion index..$^{[9,19]}$ This is primarily attributed to the lack of adequate institutional protocols or anecdotal surgeon-specific guidelines, resulting in the discarding or wasting of cross-matched but unutilized blood, thus incurring extra workload on often busy blood banks and increased operative costs while depleting a vital resource. ${ }^{[3]}$ This waste is particularly relevant for developing countries where resources are scarce and must be utilized judiciously. The crossmatch to transfusion $(\mathrm{C} / \mathrm{T})$ ratio or the transfusion index is a simple and reliable indicator of the accuracy of preoperative assessment of expected transfusions for an individual patient undergoing a particular surgical procedure. Hence, a published audit of our own institution's practices along with preoperative variables that contributed to perioperative transfusion requirements for elective spinal arthrodesis highlighted an unacceptably high $\mathrm{C} / \mathrm{T}$ ratio and based on univariate analysis, recommending two units packed cells to be arranged for patients with preoperative hemoglobin levels <9 g/dl, trauma, and adult idiopathic scoliosis (AIS) cases, or where more than two levels are being decompressed and/or arthrodesed, and for the remainder of the cases, a group and hold policy should be sufficient. ${ }^{[1]}$ Hence, a prospective validation of this individual patient-based blood ordering protocol for elective spine arthrodesis highlights implementing our recommended protocol reduced the crossmatch to transfusion ratio from 4.02 to 1.74 and an overall cost reduction of 30\%. ${ }^{[20]}$ Other papers have similarly addressed the cost-effectiveness of a protocol-based arrangement of blood products for elective surgeries, and the concept of maximum surgical blood order schedule (MSBOS) was previously developed and implemented in other developed countries, ${ }^{[8]}$ which resulted in significant cost reduction while changing practices for "routinely" or "unnecessarily" ordering blood. ${ }^{[12,14]}$
Surgical stabilization of patients with "complete" SCI is a common procedure in most spine centers of the world, despite the deficits being irreversible. ${ }^{[15]}$ Surgical fixation of spine in these patients has been advocated on the basis of "perceived" advantages, such as stabilization of unstable spine, promotion of early rehabilitation, shorter hospital stay, and prevention of progressive deformity. ${ }^{[7,21]}$ A case can be made for "incomplete" SCI, where recent literature highlights improved neurological outcome with early surgical stabilization. ${ }^{[5,22]}$ However, with reference to patients with "complete" deficits in particular, the need for surgery has remained even more controversial, ${ }^{[13]}$ with several authors advocating nonoperative management of these patients showing outcomes either comparable or superior to patients who undergo surgical stabilization. ${ }^{[2]}$ Therefore, management of these patients revolves around the prevention of complications, early rehabilitation, and re-integration into society. Hence, we aimed to compare the clinical outcomes and cost-effectiveness of surgical stabilization versus conservative management of spinal injury in patients with complete deficits, essentially from a developing country's point of view. ${ }^{[16]}$ Based on our analysis, such expenditure appears unjustified for a procedure which does not have any evidence-proven advantage. Hence, we recommend that patients with "complete" SCI should be managed nonoperatively with a provision of surgery only if they remain symptomatic.

ET has shown to provide a relatively stable and well-tolerated airway, with access for good pulmonary toilet, making oral feeding possible, permitting early ambulation, and in turn preventing orthostatic and ventilator-associated pneumonia (VAP). ${ }^{[17]}$ The review performed in our institution to evaluate the clinical outcome and cost-effectiveness of ET in isolated severe TBI patients highlights reducing the duration of mechanical ventilation and ICU stay, ICU-related morbidities, its overall effect on outcome, and at the same time being cost-effective. ${ }^{[18]}$ The scarcity of intensive care facilities in Pakistan only allows a thoroughly efficient utilization of resources and cutting down the length of ICU stay, which is the most expensive part of the treatment, reduces the load considerably. Therefore, ET should be considered in severe head injury patients requiring prolong ventilator support.

\section{CONCLUSION}

For low-middle income developing countries such as Pakistan, where without state support and insurance companies, expenses are borne by the patient themselves, especially in the private sector. Low cost initiatives without compromising health quality, as discussed, must be sought after by neurosurgical centers in developing countries, where financial and manpower constraints 
emphasize the need for implementation of smartly allocating funds.

\section{Financial support and sponsorship Nil.}

\section{Conflicts of interest}

There are no conflicts of interest.

\section{REFERENCES}

I. Alam MM, Sobani ZA, Shamim MS, Ahmad K, Minai F. Primary elective spine arthrodesis: Audit of institutional cross matched to transfused (C/T) ratio to develop blood product ordering guidelines. Surg Neurol Int 2013;4(Suppl 5):S368-72.

2. Bagnall AM, Jones L, Duffy S, Riemsma RP. Spinal fixation surgery for acute traumatic spinal cord injury. Cochrane Database Syst Re 2008; I:Cd004725.

3. Chawla T, Kakepoto GN, Khan MA. An audit of blood cross-match ordering practices at the Aga Khan University Hospital: First step towards a Maximum Surgical Blood Ordering Schedule. J Pak Med Assoc 2001;51:25।-4.

4. Deyo RA, Mirza SK, Martin BI, Kreuter W, Goodman DC, Jarvik JG. Trends, major medical complications, and charges associated with surgery for lumbar spinal stenosis in older adults. JAMA 2010;303:1259-65.

5. Fehlings MG, Vaccaro A, Wilson JR, Singh A, D WC, Harrop JS, et al. Early versus delayed decompression for traumatic cervical spinal cord injury: Results of the Surgical Timing in Acute Spinal Cord Injury Study (STASCIS). PloS One 2012;7:e32037.

6. Fernandez-Lopez S, Lennert B. Quality improvement initiatives: The missed opportunity for health plans. Am Health Drug Benefits 2009;2:297-304.

7. Geisler FH. Acute management of cervical spinal cord injury. Maryland Med J 1988;37:525-30.

8. Hardy NM, Bolen FH, Shatney $\mathrm{CH}$. Maximum surgical blood order schedule reduces hospital costs. Am Surg 1987;53:223-5.

9. Hu SS. Blood loss in adult spinal surgery. Eur Spine J 2004;। 3(Suppl I):S3-5.

10. Johnson RG, Murphy M, Miller M. Fusions and transfusions. An analysis of blood loss and autologous replacement during lumbar fusions. Spine 1989; |4:358-62.

II. Jooma R, Jalal S. Designing the first ever health insurance for the poor in Pakistan--a pilot project. J Pak Med Assoc 2012;62:56-8.

12. Lowery TA, Clark JA. Successful implementation of Maximum Surgical Blood Order Schedule. J Med Assoc Ga 1989;78:155-8.

13. McKinley W, Meade MA, Kirshblum S, Barnard B. Outcomes of early surgical management versus late or no surgical intervention after acute spinal cord injury. Arch Phys Med Rehabil 2004;85:18I8-25.

14. Napier JA, Biffin AH, Lay D. Efficiency of use of blood for surgery in south and mid Wales. Br Med J 1985;291:799-80I.

15. Smith M. Making the difference: Efficacy of specialist versus nonspecialist management of spinal cord injury. London: Spinal Injuries Association; 1999.

16. Shamim MS, Ali SF, Enam SA. Non-operative management is superior to surgical stabilization in spine injury patients with complete neurological deficits: A perspective study from a developing world country, Pakistan. Surg Neurol Int 201 I;2:166.

17. Shamim MS, Qadeer M, Murtaza G, Enam SA, Farooqi NB. Emergency department predictors of tracheostomy in patients with isolated traumatic brain injury requiring emergency cranial decompression. J Neurosurg 201।;II5:1007-I2.

18. Siddiqui UT, Tahir MZ, Shamim MS, Enam SA. Clinical outcome and cost effectiveness of early tracheostomy in isolated severe head injury patients. Surg Neurol Int 2015;6:65.

19. Torres-Claramunt R, Ramirez M, Lopez-Soques M, Salo G, Molina-Ros A, Llado A, et al. Predictors of blood transfusion in patients undergoing elective surgery for degenerative conditions of the spine. Arch Orthop Trauma Surg 2012;132:1393-8.

20. Waqas M, Shamim MS, Ujjan B, Bakhshi SK. Prospective validation of a blood ordering protocol for elective spine arthrodesis and its impact on cost reduction. Surg Neurol Int 2014;5(Suppl 7):S362-4.

21. Wilberger JE. Diagnosis and management of spinal cord trauma. J Neurotrauma 1991;8(Suppl I):S2I-8.

22. Zhu H, Feng YP, Young W, You SW, Shen XF, Liu YS, et al. Early neurosurgical intervention of spinal cord contusion: An analysis of 30 cases. Chinese Med J 2008; | $21: 2473-8$. 